\title{
Success story Rehabilitasi Ekosistem Mangrove di Pantai Karangsong Kabupaten Indramayu
}

\author{
Success story of rehabilitation mangrove ecosystem in Karangsong Beach Indramayu Regency \\ Oni $^{\mathrm{a}}$, Cecep Kusmana ${ }^{\mathrm{b}}$, Sambas Basuni ${ }^{\mathrm{c}}$ \\ ${ }^{a}$ Sekolah Pascasarjana, Institut Pertanian Bogor, Kampus IPB Darmaga Bogor, 16680, Indonesia \\ ${ }^{\mathrm{b}}$ Departemen Silvikultur, Fakultas Kehutanan, Institut Pertanian Bogor, Kampus IPB Darmaga Bogor, 16680, Indonesia \\ ${ }^{\mathrm{c}}$ Departemen Konservasi Sumber daya Hutan dan Ekowisata, Fakultas Kehutanan, Institut Pertanian Bogor, Kampus IPB Darmaga \\ Bogor, 16680, Indonesia
}

\section{Article Info:}

Received: 16 - 10 - 2018

Accepted: 05 - 03 - 2019

\section{Keywords:}

karangsong, local institution, mangrove ecosystem, rehabilitation

Corresponding Author: Oni

Sekolah Pascasarjana, Institut Pertanian Bogor

Email: onitoyib@gmail.com

\begin{abstract}
The success of Kelompok Pantai Lestari (KPL) to rehabilitate the mangrove ecosystem at Karangsong is the result of innovation in the nursery aspect at the planting site, using multiplanting planting techniques, installation of wave breaker, maintenance with fertilization and spraying, clear and clean (legal and conflict free) of land status, village level that binds all stakeholders. Management of rehabilitated mangrove ecosystem management at Karangsong beach implemented collaborative management (government, private and non-profit organizations), The analysis of the local institutional sustainability of KPL as managers of CPRs of mangrove ecosystems based on eight principles of sustainability of CPRs shows strong results of sustainability on two principles namely the boundaries of the CPRs resource area (4.36) and recognize of the right to organize and manage resources (4.13). Sustainability category one principles that have the lowest value is the principle of applying sanctions to local rules / village regulations (2.47). The average value of the eight principles of local KPL institutional sustainability managing the CPRs of the mangrove ecosystem at Karangsong is 3.54 which is included in the strong sustainability category. Management of rehabilitated mangrove ecosystem resources in Karangsong by KPL should be supported by issuing local regulations on mangrove ecosystem management in Indramayu Regency to improve the governance and ecosystem benefits of sustainable mangrove for ecological, economic and socio-cultural aspects.
\end{abstract}

How to cite (CSE Style $8^{\text {th }}$ Edition):

Oni, Kusmana C, Basuni S. 2019. Success story rehabilitasi ekosistem mangrove di Pantai Karangsong Kabupaten Indramayu. JPSL 9(3): 477-487. http://dx.doi.org/10.29244/jps1.9.3.477-487.

\section{PENDAHULUAN}

Salah satu wilayah Kabupaten Indramayu yang memiliki ekosistem mangrove adalah Desa Karangsong, Kecamatan Indramayu. Pantai Desa Karangsong selama kurun waktu 1969 sampai dengan 1983 ditumbuhi hutan mangrove dengan luas sekitar 45 ha yang berbentuk kawasan tanah timbul hasil dari sedimentasi Sungai Cimanuk (WI-IP 2001). Namun sekitar tahun 1985-an masyarakat mulai mengkonversi mangrove di sempadan pantai untuk tambak dan peruntukan non-mangrove. Masyarakat beralasan bahwa kawasan mangrove yang sudah tumbuh besar tidak memberikan manfaat ekonomi secara langsung kepada masyarakat. Kerusakan vegetasi mangrove yang sudah tumbuh besar dan menjadi kawasan daratan biasanya 
dilakukan alih fungsi lahan untuk pertambakan dan kepentingan non-mangrove. Akibat alih fungsi mangrove sejak 1983 sampai dengan 2001 kawasan pesisir Desa Karangsong tidak memiliki pelindung pantai (jalur hijau pantai), sehingga terjadi abrasi di pantai Desa Karangsong Kabupaten Indramayu.

Kondisi ekosistem mangrove di pantai utara Provinsi Jawa Barat sebagian besar telah mengalami degradasi secara kualitas maupun secara kuantitas, sehingga perlu dilakukan upaya-upaya pemulihan melalui kegiatan rehabilitasi ekosistem mangrove untuk mengembalikan fungsi ekosistem mangrove (fungsi ekologi dan fungsi ekonomi). Salah satu kawasan mangrove yang terdegradasi di pantai utara Jawa Barat adalah di Desa Karangsong. Sejak tahun 2008 sampai 2016 ada sebuah lembaga lokal yaitu Kelompok Pantai Lestari (KPL) yang melakukan upaya-upaya rehabilitasi mangrove di Pantai Karangsong sehingga kawasan pesisir yang sebelumnya terkena abrasi, saat ini pulih menjadi kawasan ekosistem mangrove yang baik. Ekosistem mangrove di Pantai Karangsong yang merupakan hasil rehabilitasi selama 10 tahun memiliki dampak positif terhadap lingkungan, sosial, dan ekonomi masyarakat sekitarnya. Keberhasilan rehabilitasi ekosistem mangrove di Karangsong tersebut perlu dikaji agar variabel-variabel kegiatan serta tematik pelaksanaan kegiatan-kegiatan oleh kelembagaan lokal tersebut dapat ditiru di tempat lain.

Tujuan penelitian ini, pertama adalah mengidentifikasi variabel-variabel kegiatan rehabilitasi mangrove yang memiliki daya ungkit keberhasilan rehabilitasi ekosistem mangrove di pantai Karangsong, dari aspek kelembagaan/organisasi, sumber daya manusia, inovasi teknologi, biaya, sistem manajemen informasi, aturan main lokal. Kedua, menganalisis keberlanjutan kelembagaan lokal berdasarkan prinsip-prinsip dan kriteria Ostrom (1990) untuk mempertahankan kelembagaan lokal kawasan rehabilitasi ekosistem mangrove di Pantai Karangsong (organisasi, SDM, teknologi, biaya, sistem manajemen informasi, aturan main).

\section{METODE}

\section{Lokasi dan Waktu Penelitian}

Penelitian dilaksanakan selama enam bulan yaitu pada Agustus 2017 sampai dengan Januari 2018 di pantai Desa Karangsong, Kecamatan Indramayu, Kabupaten Indramayu, Jawa Barat (koordinat: 06 $18^{\prime} 17.19^{\prime \prime}$ LS, 108 22'04.44” BT). Desain penelitian yang digunakan adalah action research yang merupakan praktik pengalaman terbaik (best practices management) rehabilitasi mangrove di Desa Karangsong. Secara bertahap penelitian ini menjelaskan sejarah dan kronologis rehabilitasi mangrove mulai tahun 2008 sampai 2017.

\section{Metode Pengumpulan Data}

Penelitian yang dilakukan merupakan penelitian survey. Jumlah responden sebanyak 45 reponden yang dipilih secara sengaja (purposive sampling) yaitu metode penentuan sampel berdasarkan pertimbangan tertentu, yaitu: responden pernah mengunjungi kawasan mangrove Karangsong, mengetahui keberadaan dan memahami kondisi kawasan mangrove, ikut berperan dalam proses-proses rehabilitasi mangrove, dinas atau instansi serta lembaga yang berpartisipasi dalam pelestarian mangrove Karangsong.

Wawancara terbagi atas wawancara terbuka atau mendalam dan wawancara tertutup dengan memberikan skor terhadap kuisioner. Wawancara secara tertutup dan terbuka dilakukan terhadap Kelompok Pantai Lestari (KPL) dan pemerintah desa sebagai pengelola. Wawancara tertutup dilakukan terhadap informan regulator dan para pihak serta pengelola CPRs yaitu KPL dan pemerintah desa, serta kelembagaan di tingkat desa. Wawancara tertutup dilakukan pada stakeholders seperti dinas-dinas (OPD) di Kabupaten Indramayu serta LSM, swasta dan para ahli. 


\section{Metode Analisis Data}

Kelembagaan (institusi) adalah aturan dan rambu-rambu yang digunakan sebagai panduan oleh para anggota suatu kelompok masyarakat untuk mengatur hubungan yang saling mengikat atau saling tergantung satu sama lain (Ostrom et al. 1994). North (1990) mendefinisikan kelembagaan sebagai batasan-batasan yang dibuat untuk membentuk pola interaksi yang harmonis antara individu dalam melakukan interaksi politik, sosial, dan ekonomi. Analisis keberlanjutan kelembagaan lokal pengelolaan ekosistem mangrove hasil rehabilitasi di Pantai Karangsong menggunakan teori Ostrom (1990). Prinsip-prinsip keberlanjutan kelembagaan CPRs tersebut adalah (1) Batas-batas sumber daya kawasan, (2) Kesesuaian aturan dengan kondisi lokal, (3) Pengaturan pilihan kolektif, (4) Pengawasan, (5) Sanksi yang tegas sesuai tingkat pelanggaran, (6) Mekanisme penyelesaian konflik, (7) Pengakuan hak untuk mengatur sumber daya, serta (8) Keterkaitan dalam sistem dan peraturan secara berjenjang.

Sistem penilaian menggunakan One Criteria-One Scoring, artinya bila responden hanya memilih 1 pernyataan atribut atau kriteria, maka nilai prinsip tersebut bernilai 1 (minimal). Demikian juga sebaliknya bila responden memilih dan menyetujui semua pernyataan atribut/kriteria maka nilai prinsip tersebut bernilai 5 (maksimal). Selanjutnya nilai skor dari masing-masing atribut atau kriteria di reratakan untuk menentukan posisi nilai prinsip keberlanjutan kelembagaan lokal pengelolaan ekosistem mangrove. Penilaian skor menggunakan skala Likert yang disusun dalam 5 kategori penilaian (Tabel 1).

Tabel 1 Kategori penilaian prinsip-prinsip keberlanjutan kelembagaan lokal rehabilitasi ekosistem mangrove di pantai Karangsong.

\begin{tabular}{ll}
\hline Nilai Rerata $(\ddot{\mathrm{x}})$ & \multicolumn{1}{c}{ Skala Likert } \\
\hline $1.00<\ddot{\mathrm{x}}<1.80$ & Keberlanjutannya Sangat Lemah \\
$1.80 \leq \ddot{\mathrm{x}}<2.60$ & Keberlanjutannya Lemah \\
$2.60 \leq \ddot{\mathrm{x}}<3.40$ & Cukup Berkelanjutan \\
$3.40 \leq \ddot{\mathrm{x}}<4.20$ & Keberlanjutannya Kuat \\
$4.20 \leq \ddot{\mathrm{x}}<5.00$ & Keberlanjutannya Sangat Kuat \\
\hline
\end{tabular}

\section{HASIL DAN PEMBAHASAN}

Keberhasilan rehabilitasi ekosistem mangrove di Pantai Karangsong pada aspek kelembagaan Kelompok Pantai Lestari yang dibentuk pada 17 Mei 2008, dikelola dengan gaya kepemimpinan yang demokratis (setiap keputusan kelompok merupakan hasil musyawarah). Perencanaan kegiatan rehabilitasi mangrove dilakukan secara terus menerus mulai tahun 2008 sampai dengan 2016 secara partisipatif. Persiapan lahan persemaian dan penentuan luas areal penanaman serta pemilihan jenis merupakan suatu rangkaian kegiatan perencanaan dan upaya pelaksanaan rehabilitasi mangrove (Kustanti 2011). Sedangkan menurut Taniguchi et al. (1999) tahapan budidaya mangrove meliputi: (1) persiapan lokasi penanaman, (2) pembuatan persemaian dan pengumpulan benih/propagul, (3) pelaksanaan penanaman serta (4) pengelolaan hasil rehabilitasi. Kelompok Pantai Lestari (KPL) melakukan inovasi dalam teknis rehabilitasi ekosistem mangrove di Karangsong yaitu dengan teknik penggunaan ajir bambu utuh atau bulat dengan diameter 4 sampai dengan $6 \mathrm{~cm}$. Pada Gambar 1 merupakan gambaran teknik penanaman secara multiplanting yaitu satu ajir ditanam satu bibit dan dua propagule dengan tali ikat pada dua titik (atas dan bawah) serta dilakukan pemeliharaan dengan penyemprotan seperti pada Gambar 2.

Inovasi yang dilakukan kelompok terbukti meningkatkan keberhasilan persentase tumbuh. Berdasarkan pengalaman empiris selama 8 tahun, inovasi ini membuktikan bahwa rata-rata persentase tumbuh di atas 80\%. Sistem multiplanting secara ekonomis masih bisa dilaksanakan karena peningkatan biaya penyediaan propagule bisa dialokasikan dari biaya penyulaman. Rehabilitasi ekosistem mangrove secara simultan di satu lokasi kawasan memiliki keuntungan seperti kegiatan monitoring dan evaluasi secara kontinu. 


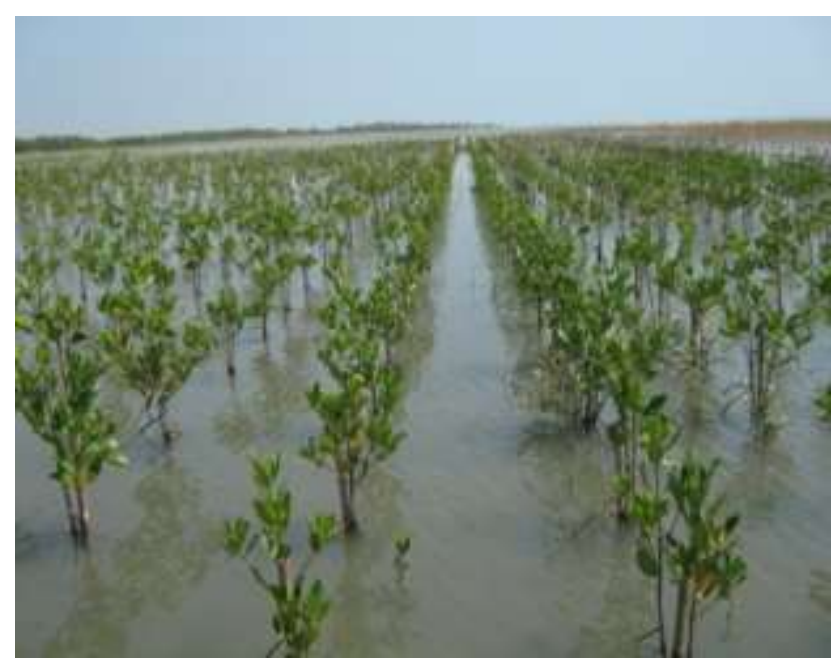

Gambar 1 Pertumbuhan mangrove dengan teknik penanaman multiplanting (Foto: Oni 2009).

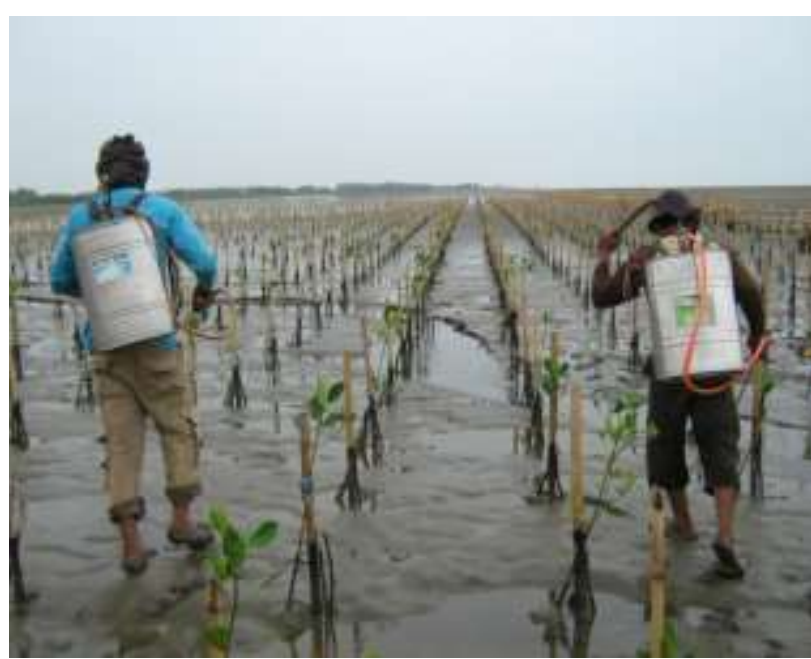

Gambar 2 Pemeliharaan dan perawatan mangrove dengan penyemprotan (Foto: Oni 2008).

Pemantapan kawasan lokasi rehabilitasi mangrove di wilayah tanah timbul dengan pembelian hak garap tanah timbul ke pemerintah desa (kuwu) dan disusun Peraturan Desa Karangsong Nomor 2 tahun 2009 tentang Pengelolaan Daerah Perlindungan Mangrove. Dampak rehabilitasi ekosistem mangrove dinikmati oleh masyarakat petambak, tumbuhnya perekonomian di lokasi eko-edu wisata mangrove, meningkatnya jenis-jenis biota perairan dan burung-burung air yang menetap di kawasan mangrove.

Tabel 2 Kronologis pemantapan kawasan rehabilitasi mangrove di Pantai Karangsong Indramayu.

\begin{tabular}{|c|c|c|}
\hline No & Uraian & Dokumen dan Tanggal \\
\hline 1 & $\begin{array}{l}\text { Rapat Pembentukan Kelompok Pantai Lestari } \\
\text { Karangsong }\end{array}$ & Tanggal 17 Mei 2008 \\
\hline 2 & $\begin{array}{l}\text { SK. Domisili Kelompok Pantai Lestari } \\
\text { Karangsong }\end{array}$ & $\begin{array}{l}\text { Surat Domisili No.38/Ds.2019/V/2008 } \\
\text { Tanggal } 21 \text { Mei } 2008\end{array}$ \\
\hline 3 & $\begin{array}{l}\text { SK. Kelompok Kerja (Pokja) Pengelolaan } \\
\text { Ekosistem Mangrove di Kabupaten Indramayu }\end{array}$ & $\begin{array}{l}\text { Keputusan Bupati No.665/Kep.442-Dishutbun/2009 } \\
\text { Tanggal 05 Januari } 2009\end{array}$ \\
\hline 4 & $\begin{array}{l}\text { Rekomendasi Lokasi Penanman dan Kesiapan } \\
\text { Menerbitkan Perdes }\end{array}$ & $\begin{array}{l}\text { Surat Pernyataan Kuwu No.01/Ds.2019/SP/2009 } \\
28 \text { Mei } 2009\end{array}$ \\
\hline 5 & $\begin{array}{l}\text { Peraturan Desa Pengelolaan Daerah } \\
\text { Perlindungan Mangrove Desa Karangsong }\end{array}$ & $\begin{array}{l}\text { No. } 02 \text { Tahun } 2009 \\
\text { Tanggal } 09 \text { Desember } 2009\end{array}$ \\
\hline 6 & $\begin{array}{l}\text { Hak Kelola Tanah Timbul untuk Penanaman } \\
\text { Mangrove Desa Karangsong }\end{array}$ & $\begin{array}{l}\text { Surat Keterangan Desa No.09/Ds.2019/SKD/I/2010 } \\
\text { Tanggal 04 Januari } 2010\end{array}$ \\
\hline 7 & $\begin{array}{l}\text { SK. Penetapan Lokasi Pusat (mangrove center) } \\
\text { di Kabupaten Indramayu }\end{array}$ & $\begin{array}{l}\text { Keputusan Bupati No.522.1/Kep.189-A-4- } \\
\text { Dishutbun/2013 } \\
\text { Tanggal 24 Desember } 2013\end{array}$ \\
\hline 8 & $\begin{array}{l}\text { SK. Penetapan Kawasan Pusat Mangrove Desa } \\
\text { Karangsong sebagai Pusat Restorasi dan } \\
\text { Pembelajaran Mangrove di Kabupaten } \\
\text { Indramayu }\end{array}$ & $\begin{array}{l}\text { Keputusan Bupati No.523.05/Kep.152-A- } \\
\text { Diskanla/20014 } \\
\text { Tanggal 07 April } 2014\end{array}$ \\
\hline
\end{tabular}

Kegiatan pemantapan kawasan ekosistem mangrove dapat dilakukan melalui kegiatan penataan batasbatas kawasan, penentuan lembaga pengelola kawasan, tata kelola kawasan sesuai peran dan tanggung jawab serta aturan main (rule of game) seperti penyusunan Peraturan Desa Karangsong Nomor 2 tahun 2009 tentang Pengelolaan Daerah Perlindungan Mangrove. Pemantapan kawasan melibatkan para pihak yang 
memiliki kepentingan terhadap sumber daya kawasan sehingga dapat disepakati secara bersama-sama. Kronologis pemantapan kawasan rehabilitasi ekosistem mangrove Karangsong disajikan pada Tabel 2. Pemantapan kawasan ekosistem mangrove Karangsong merupakan hal yang penting karena terdapat $7 \%$ responden merasa khawatir terjadi konversi menjadi kawasan non-mangrove.

Variabel-variabel yang memiliki daya ungkit keberhasilan rehabilitasi ekosistem mangrove di Pantai Karangsong adalah kelembagaan Kelompok Pantai Lestari dengan menerapkan manajemen kolaboratif (pemerintah, swasta dan lembaga nirlaba) serta rehabilitasi mangrove dilakukan secara terus menerus mulai tahun 2008 sampai dengan 2016. Keberhasilan rehabilitasi mangrove secara teknis ditunjang dengan inovasi teknis penanaman multiplanting (satu ajir ditanam dengan satu bibit dan dua propagule) dengan tali ikat pada dua titik (atas dan bawah) seperti pada Gambar 1. Teknis rehabilitasi ekosistem mangrove di Karangsong dilakukan dengan teknik penggunaan ajir bambu utuh atau bulat dengan diameter $4 \mathrm{~cm}$ sampai dengan $6 \mathrm{~cm}$. Pemasangan Alat Pemecah Ombak (APO) dari bahan lokal serta sediment trap berupa waring berbahan nilon (Gambar 3). Kegiatan pemeliharaan dilakukan dengan cara pemupukan menggunakan Pupuk Pelengkap Cair (PPC) dan penyemprotan pestisida, fungisida serta zat pengatur tumbuh (ZPT). Areal penanaman memiliki status tanah yang clear dan clean (bebas konflik dan legal) dengan cara pembelian hak garap (hak kelola) tanah timbul ke pemerintah desa (kuwu) dan pembelian empang-empang yang rusak di kawasan tanah timbul. Langkah berikutnya adalah dibuat peraturan lokal pada tingkat desa yang mengikat seluruh stakholders.

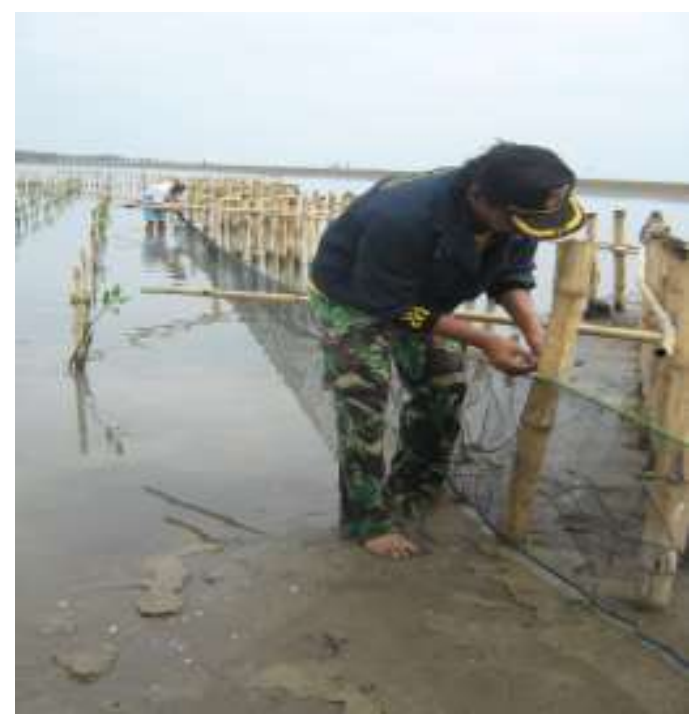

Gambar 3 Pemasangan APO dan sediment trap (Foto: Oni 2008).

Pemanfaatan sumber daya ekosistem mangrove oleh masyarakat lokal menurut Kusmana dan Sukristijiono (2016) meliputi manfaat langsung dan tidak langsung dari produk kayu mangrove serta manfaat ekosistem mangrove. Selain itu, ekosistem mangrove memiliki manfaat potensial seperti area konservasi dan mitigasi bencana di kawasan pesisir. Ekosistem mangrove hasil rehabilitasi di Karangsong sedikitnya melindungi area tambak dari abrasi seluas \pm 100 ha. Jasa lingkungan ekosistem mangrove Karangsong sejak tahun 2015 menjadi kawasan tujuan ekowisata dan wisata pendidikan lingkungan. Jumlah kunjungan ekowisata di kawasan ekosistem mangrove Karangsong pada kurun waktu tahun 2015 sampai 2017 terus meningkat. Grafik peningkatan kunjungan ekowisata ekosistem mangrove Karangsong disajikan pada Gambar 1. 


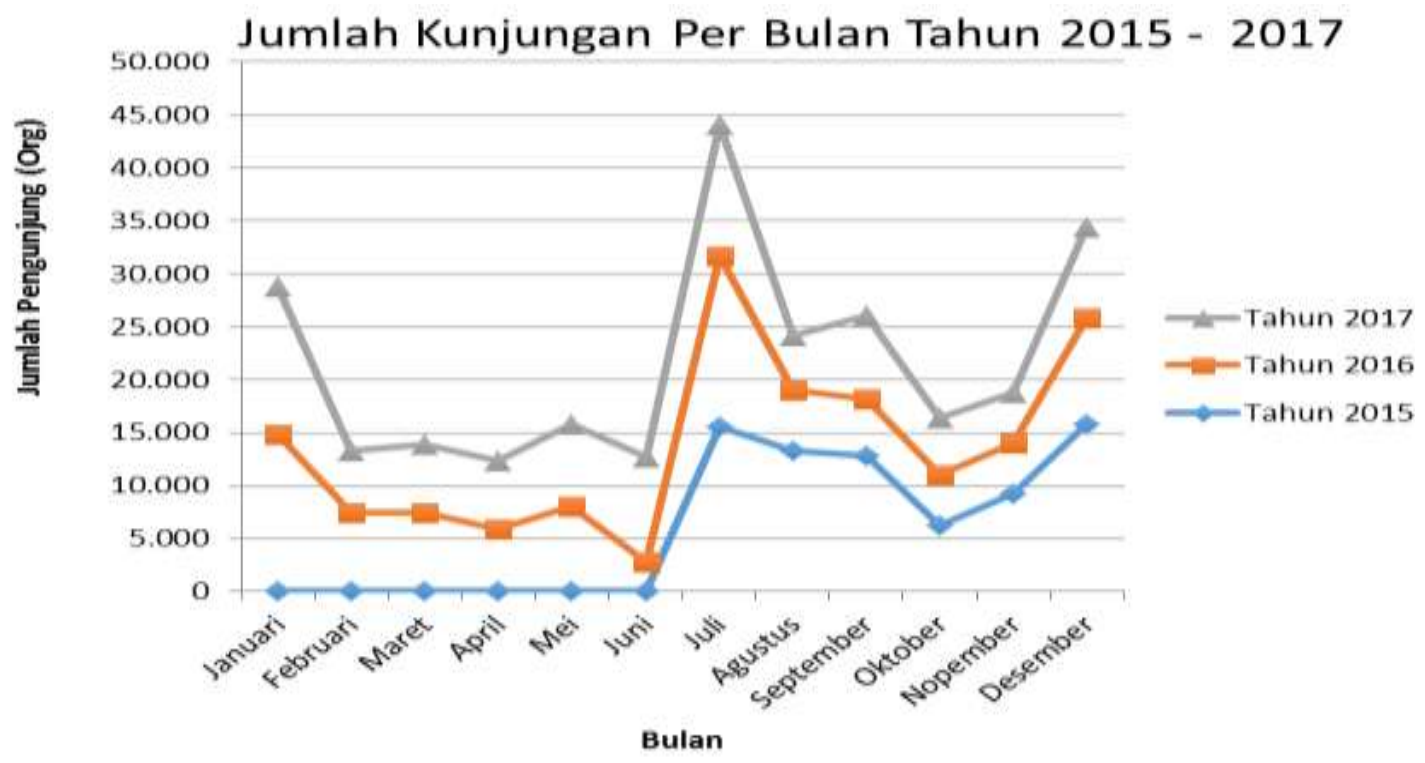

Gambar 4 Jumlah kunjungan ekowisata mangrove.

Dampak ekonomi keberadaan ekosistem mangrove Karangsong mampu meningkatkan penyerapan tenaga kerja dan struktur perekonomian di Desa Karangsong. Penyerapan tenaga kerja pada sektor petugas pengelola ekowisata sebanyak 20 orang, petugas pintu gerbang masuk kawasan sebanyak 50 orang yang dikelola oleh Karang Taruna dengan sistem shift. Aktivitas perekonomian tumbuh di sekitar kawasan ekowisata mangrove berupa pembangunan kios-kios (warung) sebanyak 58 kios. Dampak sosial rehabilitasi ekosistem mangrove di Karangsong saat ini semakin meningkatkan kepedulian terhadap kawasan mangrove terutama para petambak di sekitar kawasan karena tambaknya terlindung dari abrasi. Selain itu peran serta masyarakat terutama pemilik kios-kios di sekitar kawasan dalam menjaga sumber daya mangrove karena keberadaan mangrove berpengaruh terhadap kunjungan ekowisata mangrove.

Dampak rehabilitasi ekosistem mangrove di pantai Desa Karangsong secara nyata telah mendorong kehadiran burung-burung air dan fauna lainnya berkembang di kawasan hasil rehabilitasi. Gunawan et al. (2017) menyebutkan bahwa terdapat 12 famili burung terdiri dari 20 spesies ditemukan di mangrove dan vegetasi pesisir di Karangsong. Terdapat 8 spesies burung air ditemukan di habitat bakau dan burung-burung tersebut sangat umum hadir di mangrove Karangsong dan beberapa di antaranya adalah penghuni sementara. Rekapitulasi data kegiatan rehabilitasi di Desa Karangsong, Desa Pabean Udik dan Desa Brondong sejak tahun 2008 sampai dengan 2016 sudah tertanam seluas \pm 62.30 ha. Gunawan et al. (2017) menyebutkan bahwa rehabilitasi ekosistem mangrove di Karangsong terdiri dari 6 spesies mangrove yaitu Rhizophora mucronata, Rhizophora stylosa, Rhizophora apiculata, Avicennia marina, Avicennia alba, Sonneratia caseolaris dan 3 spesies pohon vegetasi pesisir yaitu Terminalia catappa L., Casuarina equisetifolia L., dan Ziziphus mauritiana Lam.

Prinsip-prinsip keberlanjutan pengelolaan sumber daya alam oleh kelembagaan lokal KPL mengacu pada 8 prinsip keberlanjutan teori Osrtom (1990) dan kriteria-kriteria yang ditentukan pada setiap prinsip dianalisis berdasarakan hasil wawancara terhadap responden dan informan secara purposive sampling terhadap 45 informan. Menurut Yulianto (2017) peran kelembagaan masyarakat rehabilitasi mangrove dan pola partisipatif merupakan hal penting dalam pengelolaan terpadu ekosistem mangrove untuk mendukung sektor perikanan di Indramayu.

Berdasarkan penilaian kategori keberlanjutan kelembagaan lokal pengelola CPRs mengacu pada Tabel 3 , analisis terhadap 8 prinsip-prinsip keberlanjutan pengelolaan menunjukan bahwa prinsip pertama yaitu batas-batas sumber daya kawasan ekosistem mangrove Karangsong memiliki nilai tertinggi yaitu 4.36 dengan kategori keberlanjutan sangat kuat (KSK). Status batas-batas kawasan sumber daya khususnya hutan 
yang berkaitan hak kepemilikan (property right) dan pengakuan sistem tenurial adalah sebagai kekuatan untuk mengatur hak dan kewajiban serta hak tanggung jawab terhadap sumber daya hutan tersebut (Khalik et al. 2011).

Prinsip kedua adalah kesesuaian aturan dengan kondisi lokal yaitu Peraturan Desa Nomor 2 Tahun 2009 tentang Pengelolaan Daerah Perlindungan Mangrove (DPM) Desa Karangsong memiliki nilai 3.36 dengan kategori cukup berkelanjutan (CB). Pembuatan peraturan desa tentang DPM merupakan aturan lokal tertulis sebagai upaya untuk mengoptimalkan peran kelembagaan, walaupun hasil penilaian masuk kategori cukup berkelanjutan namun setidaknya masyarakat, kelompok, dan pemerintah desa mempunyai kemauan kuat untuk mengatur sumber daya yang bersifat milik bersama (CPRs). Peran kelembagaan lokal dalam pengelolaan mangrove Karangsong telah disepakati dan tercantum pada peraturan desa tersebut pada pasal 11 yang berbunyi "pengelolaan ekosistem mangrove hasil rehabilitasi ditunjuk Kelompok Pantai Lestari Karangsong". Kustanti et al. (2014) memberikan contoh model pemberian hak kepemilikan tanah timbul berhutan mangrove oleh Kabupaten Lampung Timur kepada Universitas Lampung merupakan lembaga yang dipercaya (trusted institution) dan diterima (acceptability) di masyarakat.

Prinsip ketiga tentang pengaturan pilihan kolektif terhadap keterlibatan dan atau keterwakilan membuat aturan pilihan kolektif pengelolaan ekosistem mangrove Karangsong (nilai 3.93) masuk dalam kategori keberlanjutan kuat (KK). Hasil ini memiliki pengertian bahwa pilihan kolektif untuk mengatur sumber daya milik bersama akan semakin kuat. Piihan kolektif dibuat berdasarkan keinginan bersama dari berbagai pihak, dari berbagai kepentingan dan level kebijakan di tingkat desa. Tingkat pilihan kolektif adalah pengambilan keputusan oleh sekumpulan orang yang memiliki otoritas tertentu namun keputusannnya bersifat menentukan dan memaksa individu di dalam yuridiksi administratif/hukum maupun sosial (Kartodihardjo 2006). Pengambilan keputusan pilihan kolektif pada penelitian ini pada tingkat desa dalam bentuk peraturan desa tentang DPM. Aturan tingkat pilihan kolektif dapat diubah oleh aksi di tingkat pilihan konstitusional (desa).

Prinsip keempat tentang kegiatan pengawasan dan monitoring terhadap kawasan ekosistem mangrove Karangsong memiliki kategori cukup keberlanjutan (CB) dengan nilai skor 3.24. Prinsip keempat ini merupakan tanggung jawab KPL yang telah mendapatkan amanat dari Perdes No. 2 Tahun 2009 tentang DPM Karangsong pada pasal 11 yang berbunyi bahwa pengelolaan daerah perlindungan mangrove hasil rehabilitasi dikelola oleh KPL. Konsekuensi dari pelimpahan hak kelola ke KPL, Schlager dan Ostrom (1992) membagi hak kepemilikan atas sumber daya alam dan lingkungan terutama yang memiliki karakteristik sebagai CPR seperti sumber daya perikanan menjadi access (hak akses), withdrawal (hak memanfaatkan), management (hak manajemen), exclusion (hak eksklusi), dan alienation (hak alienasi). Hak akses merupakan hak untuk memasuki suatu wilayah di mana sumber daya alam dan lingkungan berada, misalnya hak untuk memasuki suatu wilayah perairan. Hak memanfaatkan merupakan hak untuk mengambil manfaat dari sumber daya alam dan lingkungan yang ada di suatu wilayah tertentu, misalkan hak untuk menangkap sumber daya ikan (Schlager dan Ostrom 1992).

Penilaan kategori keberlanjutan prinsip kelima yaitu penerapan sanksi yang tegas sesuai tingkat pelanggaran terhadap Perdes Nomor 2 Tahun 2009 tentang Pengelolaan DPM Karangsong memiliki nilai terendah yaitu 2.47 dengan kategori keberlanjutan lemah (KL). Penerapan sanksi sesuai dengan peratuaran desa masih lemah karena KPL sebagai pengelola tidak memiliki otoritas penuh dalam proses penindakan terhadap pelanggar. Hak penindakan terhadap pelanggar pada peraturan desa minimal dilakukan oleh pemerintah desa dan atau aparat penegak hukum. Tugas KPL umumnya mengingatkan pada pelanggar dalam bentuk teguran dan surat pernyataan tidak untuk mengulangi kembali perbuatannya.

Prinsip keenam tentang mekanisme penyelesaian konflik yang berasal dari internal dan eksternal kelompok pengelola ekosistem mangrove Karangsong memperoleh nilai 3.11 dengan kategori cukup keberlanjutan (CB). Mekanisme penyelesaian konfilk di kawasan mangrove Karangsong diselesaikan dengan musyawarah secara berjenjang sesuai tingkat permasalahan. Konflik yang rendah atau kecil dapat 
diselesaikan pada tingkat pengelola CPRs namun bila konflik yang berhubungan dengan masalah yang efeknya mencakup masyarakat desa dan atau masalah dengan pihak luar desa maka diselesaikan pada tingkat pemerintahan desa.

Keberlanjutan pada prinsip ketujuh tentang pengakuan hak untuk mengatur dan mengelola sumber daya ekosistem mangrove Karangsong oleh KPL, mendapat pengakuan hak yang tinggi dengan nilai 4.13 termasuk dalam kategori keberlanjutan kuat (KK). Prinsip pengakuan hak untuk mengatur dan mengelola kawasan eksositem mangrove hasil rehabilitasi di Karangsong sesuai dengan Peraturan Desa Nomor 2 tahun 2009 tentang DPM menjelaskan bahwa pasal 11 menyatakan hak kelola DPM diserahkan ke KPL. Hasil penilaian dalam penelitian ini memiliki nilai tertinggi setelah batas-batas kawasan sumber daya. Kartodihardjo (2006) menyebutkan bahwa pengakuan atas hak didasarkan pada hukum posistif agar sejalan dengan administrasi pemerintahan yang berjalan. Namun demikian hak dalam konteks sosial memerlukan pengakuan masyarakat yang diwujudkan melalui proses-proses tertentu. Hak yang dimiliki masyarakat apabila dikaitkan dengan fungsi sumber daya hutan (mangrove) dengan batasan-batasan tertentu, sebagai contoh hutan dengan fungsi lindung. Menurut Pakpahan (1989) konsep kepemilikan (property) muncul dari konsep hak (rights) dan kewajiban (obligations) yang didefinisikan atau diatur oleh hukum, adat, dan tradisi atau konsensus yang mengatur hubungan antar anggota masyarakat dalam hal kepentingannnya terhadap sumber daya.

Tabel 3 Penilaian prinsip dan kriteria keberlanjutan kelembagaan lokal KPL pengelola ekosistem mangrove di Karangsong, Indramayu

\begin{tabular}{|c|c|c|c|}
\hline No. & $\begin{array}{c}\text { Prinsip-prinsip dan Kriteria Keberlanjutan Kelembagaan Lokal } \\
\text { Pengelola CPRs }\end{array}$ & Nilai Total & $\begin{array}{l}\text { Nilai } \\
\text { Rerata }(\ddot{x})\end{array}$ \\
\hline 1 & Batas-batas sumber daya kawasan ekosistem mangrove Karangsong & 196 & 4.36 \\
\hline 2 & $\begin{array}{l}\text { Kesesuaian Aturan lokal Peraturan Desa No. } 02 \text { Tahun } 2009 \text { tentang } \\
\text { Pengelolaan Daerah Perlindungan Mangrove (DPM) di Desa } \\
\text { Karangsong }\end{array}$ & 151 & 3.36 \\
\hline 3 & $\begin{array}{l}\text { Keterlibatan keterwakilan dalam membuat aturan pilihan kolektif } \\
\text { pengelolaan eksositem mangrove }\end{array}$ & 177 & 3.93 \\
\hline 4 & $\begin{array}{l}\text { Kegiatan pengawasan dan monitoring terhadap kawasan ekosistem } \\
\text { mangrove }\end{array}$ & 146 & 3.24 \\
\hline 5 & $\begin{array}{l}\text { Sanksi yang tegas sesuai tingkat pelanggaran Terhadap Peraturan } \\
\text { Desa No. } 02 \text { Tahun } 2009 \text { tentang Pengelolaan DPM }\end{array}$ & 111 & 2.47 \\
\hline 6 & $\begin{array}{l}\text { Mekanisme penyelesaian konflik, yang berasal dari internal dan } \\
\text { konflik dari eksternal }\end{array}$ & 140 & 3.11 \\
\hline 7 & $\begin{array}{l}\text { Pengakuan hak untuk mengatur dan mengelola sumber daya } \\
\text { ekosistem mangrove Karangsong }\end{array}$ & 186 & 4.13 \\
\hline 8 & $\begin{array}{l}\text { Keterkaitan/kesesuaian dalam sistem dan peraturan secara } \\
\text { berjenjang (sesuai aturan yang lebih atas/tinggi) }\end{array}$ & 168 & 3.73 \\
\hline
\end{tabular}

Sumber: Ostrom (1990) dan data primer diolah (2018).

Pengelolaan ekosistem mangrove Karangsong oleh KPL terhadap keterkaitan atau kesesuaian dalam sistem dan peraturan secara berjenjang atau peraturan lebih tinggi memiliki nilai 3.73 dengan kategori keberlanjutan kuat (KK). Lokasi rehabilitasi ekosistem mangrove harus sesuai dengan peraturan-peraturan secara berjenjang yang lebih tinggi. Hasil penilaian menunjukan kesesuaian aturan dengan peraturan yang lebih tinggi yaitu mulai tingkat kecamatan disesuaikan dengan RDTR Kecamatan Indramayu, lokasi 
rehabilitasi ekosistem mangrove ditetapkan sebagai kawasan sempadan pantai. Selaras dengan RDTR, berdasarkan RTRW Kabupaten Indramayu Tahun 2011 sampai dengan 2013 pada Lampiran V peta rencana pola ruang sebagai kawasan sempadan pantai. Peraturan Derah Provinsi Jawa Barat No. 06 Tahun 2011 tentang Pengelolaan Ekosistem Mangrove dan Hutan Pantai pada pasal 13 memberikan amanat tentang rehabilitasi dan konservasi mangrove di luar kawasan hutan. Prinsip kedelapan ini memiliki kategori keberlanjutan kuat artinya bahwa kegiatan dan pengelolaan eksistem mangrove sudah sesuai dengan regulasi dan peraturan yang dikeluarkan oleh pemerintah.

Pengalaman terbaik ini dapat direplikasikan di wilayah lain untuk meningkatkan keberhasilan rehabilitasi mangrove. Keberhasilan rehabilitasi ekosistem mangrove di Pantai Karangsong merupakan kerja keras dari berbagai pihak seperti KPL, Pemerintah Desa Karangsong, Pemerintah Daerah, Dinas Perikanan dan Kelautan Kabupaten Indramayu, CSR PT. Pertamina RU VI Balongan, lembaga swadaya masyarakat serta masyarakat sekitar kawasan. Peran serta para pihak dalam pengelolaan ekosistem mangrove di Angke Kapuk Jakarta diperlukan agar tercipta sistem kelembagaan seimbang dan saling mendukung sesuai peran dan fungsinya (Sasongko et al. 2014). Keberhasilan ini dapat dijadikan sebagai contoh dalam mengimplementasikan manajemen kolaboratif pada sektor pengelolaan ekosistem mangrove di wilayah pesisir. Hal terpenting dari manajemen kolaborasi memiliki kesamaan dalam tujuan sehingga akan mempermudah untuk menyatukan harapan dan tujuan serta memberi arah dalam pengelolaan kawasan (Sasongko et al. 2014).

Memperhatikan kondisi politik lokal desa Karangsong terhadap kelestarian ekosistem mangrove hasil rehabilitasi diduga akan berpengaruh bila terjadi pergantian kuwu (kepala desa). Berdasarkan jawaban responden, sebesar 93\% menyatakan optimis terhadap kawasan ekosistem mangrove hasil rehabilitasi yang akan tetap lestari. Di sisi lain, sebanyak 7\% responden menyatakan bahwa ekosistem mangrove hasil rehabilitasi akan berubah fungsi dan atau terjadi konversi untuk tujuan non-mangrove.

Sebagai upaya untuk mempertahankan kawasan ekosistem hasil rehabilitasi di Karangsong semua responden (100\%) menyatakan bahwa perlu diterbitkan peraturan daerah Kabupaten Indramayu tentang pengelolaan ekosistem mangrove di wilayah pesisir. Alasan untuk menerbitkan peraturan daerah untuk mempertegas arah tata kelola dan status kawasan ekosistem mangrove Karangsong (44\%). Alasan kedua untuk keberlanjutan ekosistem mangrove yang berfungsi ekologi, ekonomi dan pencegahan pemanasan global (29\%). Alasan ketiga karena kawasan sudah memiliki Perdes, SK Bupati sehingga perlu diterbitkan peraturan daerah (13\%), serta alasan aturan yang lebih tinggi dari Perdes (13\%).

\section{SIMPULAN}

Variabel-variabel yang memiliki daya ungkit keberhasilan rehabilitasi ekosistem mangrove di Pantai Karangsong adalah kelembagaan Kelompok Pantai Lestari dengan menerapkan manajemen kolaboratif (pemerintah, swasta dan lembaga nirlaba). Lokasi rehabilitasi memiliki status tanah clear dan clean (bebas konflik dan legal), serta dibuat Peraturan Desa Nomor 02 Tahun 2009 tentang DPM yang mengikat seluruh stakeholders. Teknis penanaman dengan ajir bambu bulat, metode tanam multiplanting dan pemasangan alat pemecah ombak (APO), pemeliharaan, perawatan dan monitoring vegetasi mangrove.

Analisis kelembagaan lokal KPL sebagai pengelola CPRs ekosistem mangrove terhadap 8 prinsip keberlanjutan CPRs yang menunjukkan hasil keberlanjutan sangat kuat (KSK) pada prinsip pertama yaitu batas-batas kawasan sumberdaya CPRs (4.36). Terdapat tiga prinsip yang memiliki keberlanjutan kuat (KK) yaitu prinsip pengakuan hak untuk mengatur dan mengelola sumber daya (4.13), prinsip keterwakilan membuat aturan kolektif (3.93) dan kesesuaian aturan dengan yang lebih atas (3.73). Kategori yang memiliki cukup berkelanjutan (CB) merupakan tiga prinsip yang memiliki nilai 3.36 pada prinsip kesesuaian aturan lokal dan pengawasan dan monitoring sumber daya (3.24) serta prinsip mekanisme penyelesaian konflik internal dan eksternal (3.11). Adapun nilai terendah adalah prinsip penerapan sanksi terhadap aturan lokal/peraturan desa (2.47) dengan kategori keberlanjutan lemah (KL). Nilai rerata terhadap delapan prinsip 
keberlanjutan kelembagaan lokal KPL yang mengelola CPRs ekosistem mangrove di Karangsong adalah 3.54 yang termasuk dalam kategori keberlanjutan kuat (KK).

Pengelolaan sumber daya ekosistem mangrove hasil rehabilitasi di Karangsong oleh KPL harus ditunjang dengan menerbitkan peraturan daerah tentang pengelolaan ekosistem mangrove di Kabupaten Indramayu untuk meningkatkan tata kelola dan manfaat ekosistem mangrove yang berkelanjutan dari aspek ekologi, ekonomi dan sosial budaya.

\section{DAFTAR PUSTAKA}

Gunawan H, Sugiarti S, Iskandar. 2017. Dynamics of mangrove community in revegetation area of Karangsong, north coast of Indramayu District, West Java, Indonesia. Biodiversitas. 18(2):659-665.

Kartodihardjo H. 2006. Membangkitkan Kembali dan Meningkatkan Peluang Kerja di Sektor Kehutanan dalam Rangka Ketahanan Nasional. Jakarta: Lemhanas.

Khalik I, Kusmana C, Basuni S. 2011. Analisis kelembagaan pengelolaan daerah penyangga Taman nasional Kerinci Seblat: Studi kasus di eks PT. Maju Jaya Raya Timber Kabupaten Bengkulu Utara Provinsi Bengkulu. Jurnal Pengelolaan Sumberdaya Alam. 1(1):01-09.

Kusmana C, Sukristijiono. 2016. Mangrove resource uses by local community in Indonesia. Jurnal Pengelolaan Sumberdaya Alam. 6(2):217-224.

Kustanti A. 2011. Manajemen Hutan Mangrove. Bogor: Penerbit IPB Press.

Kustanti A, Nugroho B, Darusman D, Kusmana C, Nurrochmat DR. 2014. Evolusi hak kepemilikan dalam pengelolaan ekosistem hutan mangrove di Lampung Mangrove Center. Risalah Kebijakan Pertanian dan Lingkungan. 1(3):143-158.

North DC. 1990. Institutions, Institutional Change and Economics Performance. England: Cambridge University Press.

Ostrom E, Gardner R, Walker J. 1994. Rules, Games, and Common-Pool Resources. Michigan: University of Michigan Press.

Ostrom E. 1990. Governing the Commons, The Evolution of Institutions for Collective Action. England: Cambridge University Press.

Pakpahan A. 1989. Kerangka analitik untuk penelitian rekayasa sosial: perspektif ekonomi institusi. Di dalam: Pasandaran et al. (editor) 1989. Evolusi Kelembagaan Pedesaan Di Tengah Perkembangan Teknologi Pertanian. Bogor: Pusat Penelitian Agro Ekonomi. Badan Penelitian dan Pengembangan Pertanian.

Sasongko DA, Kusmana C, Ramadan H. 2014. Strategi pengelolaan Hutan Lindung Angke Kapuk. Jurnal Pengelolaan Sumberdaya Alam. 4(1):35-42.

Schlager E, Ostrom E. 1992. Property-rights regimes and natural resources: A conceptual analysis. Land Economics. 68(3):249-262.

Taniguchi K, Takashima S, Suko O. 1999. Tehe Silviculture Manual For Mangroves. Bali: Ministry of Forestry and Estate Crops in Indonesia \& JICA (Japan International Coorporation Agency). The Development of sustainable Mangrove management Project. Bali. PT. Indografika Utama.

[WI-IP] Wetlands International Indonesian Programs. 2001. Laporan Kegiatan "Pengelolaan Wilayah Pesisir Kabupaten Indramayu”. Wetlands International Indonesian Programs. Bogor: (tidak dipublikasikan).

Yulianto G. 2017. Desain kebijakan pengelolaan terpadu mangrove dan perikanan (studi kasus di Kabupaten Indramayu, Jawa Barat) [disertasi]. Bogor: Institut Pertanian Bogor. 